\title{
"Infidelidad, culpa, divorcio e indemnización de perjuicios en el derecho matrimonial argentino y chileno"*
}

\section{Susan Turner Saelzer ${ }^{* *}$}

Resumen. El derecho matrimonial presenta en Chile y Argentina una evolución histórica similar durante los siglos xIx y xx, tendencia que se desvanece en algunos aspectos con la entrada en vigencia en Argentina del nuevo Código Civil y Comercial de la Nación en el año 20 I 5 . Este trabajo aborda uno de esos aspectos, el de la eventual responsabilidad civil derivada de la infracción del deber de fidelidad entre los cónyuges, cuestión íntimamente relacionada con el divorcio por culpa, intentando extraer conclusiones útiles de la reforma argentina para el derecho chileno.

Palabras clave: deber de fidelidad, indemnización de perjuicios, divorcio por culpa.

\section{Infidelity, Fault, Divorce, and Compensation for Damages in Argentinean and Chilean Marriage Law}

Aвstract. Argentinean and Chilean marriage law display a similar historical evolution during the igth and 2oth centuries; a tendency that, however, withers

Fecha de recepción: 4 de diciembre de 2017 . Fecha de aceptación: 30 de abril de 2018 .

Para citar el artículo: Túrner Saelzer, S., "Infidelidad, culpa, divorcio e indemnización de perjuicios en el derecho matrimonial argentino y chileno", Revista de Derecho Privado, Universidad Externado de Colombia, n. ${ }^{\circ}$ 35, julio-diciembre de 2018, I05-I28. Dor: https://doi. org/Io. I860I/or 234366.135 .05

* Doctora en Derecho, Universidad de Göttingen, Alemania. Profesora de Derecho Civil, Universidad Austral de Chile, Valdivia, Chile. Correo electrónico: sturner@uach.cl

No hay palabras suficientes para agradecer apropiadamente a la Dra. Aída Kemelmajer de Carlucci por abrirme las puertas de su biblioteca personal en la ciudad de Mendoza, haciendo posible este trabajo. 
away with the enactment in Argentina of the new Civil and Commercial Code in 20I5. This article studies one of its innovations, the possible civil liability resulting from the breach of the spousal fiduciary duty and its implications with respect to fault divorce, in order to draw conclusions from the reform that could be used to shed light on potential developments in Chilean law.

Keywords: Spousal fiduciary duty, compensation for damages, fault divorce.

Sumario. Introducción. I. El deber de fidelidad entre cónyuges y las consecuencias de su incumplimiento en Argentina. A. Fidelidad y adulterio en el código civil de Vélez Sarsfield vigente hasta el I de agosto de 2015. B. Divorcio en el código civil de Vélez Sarsfield vigente hasta el I de agosto de 2015. C. La indemnización de perjuicios por incumplimiento del deber de fidelidad durante la vigencia del código civil de Vélez Sarsfield. II. El deber de fidelidad en el código civil y comercial y las consecuencias de su incumplimiento. A. El deber de fidelidad en el código civil y comercial. B. El divorcio en el código civil y comercial. C. Indemnización de perjuicios por infracción del deber moral de fidelidad. III. La experiencia argentina confrontada con la realidad chilena. Conclusiones. Referencias.

\section{Introducción}

El derecho de familia chileno comparte con el argentino un cierto recorrido histórico en materia de regulación legal del matrimonio. Códigos civiles decimonónicos que mantuvieron el matrimonio católico como única unión legitimada civilmente y fundadora de la familia; posterior modificación de dichos códigos por "leyes laicas" en la década de i 880 que reivindicaron el matrimonio heterosexual como institución civil, regida por el derecho civil, pero manteniendo su carácter indisoluble; consagración del deber de fidelidad entre los cónyuges acompañada de una tardía despenalización del adulterio durante los años noventa del siglo xx; recepción, a fines de dicho siglo y comienzos del xxI, del divorcio vincular como causal de terminación del matrimonio, con un lugar preponderante asignado a la culpa de uno de los cónyuges, constituyen hitos comunes en la historia del derecho matrimonial de ambos países ${ }^{\mathrm{I}}$.

I Para una breve descripción de la evolución normativa del estatuto matrimonial argentino, cfr. Bовrosky, J., "Matrimonio y divorcio", en Krasnow, A. (dir.), Manual de derecho de familia, Buenos Aires, Astrea, 20I6, 78-80. Asimismo, Giondano, V., "La reforma del código civil: pasado y presente desde una perspectiva de género", Mora (B. Aires), vol. 2 I, n. ${ }^{\circ}$ I, junio, 2015, disponible en: http://www.scielo.org.ar/scielo.php?script=sci_arttext\&pid=SI 853 -00 IX 2015000 I 00006 [consultado el ro de octubre de 2015]. 
Sin embargo, el nuevo Código Civil y Comercial de la Nación ${ }^{2}$ (en adelante, ccyc) ha marcado la separación de estas rutas paralelas. Más allá de la evidente separación del régimen matrimonial argentino producto de la recepción legislativa del matrimonio igualitario en $20 \mathrm{Io}^{[3]}$, modificación que en Chile hasta ahora solo se refleja en la existencia de un proyecto de ley sobre la materia ${ }^{4}$, la entrada en vigencia del nuevo código el I de agosto de 2015 implica un giro en la evolución de los estatutos matrimoniales de ambos países. En efecto, el derecho de familia argentino actual optó por despojar expresamente de contenido jurídico al deber de fidelidad de los cónyuges y por eliminar el divorcio por falta imputable al otro, resolviendo por esta vía la cuestión acerca de la procedencia de la indemnización de perjuicios en caso de incumplimiento de dicho deber. En el derecho chileno, en cambio, la tradicional discusión acerca de la calificación del deber de fidelidad -meramente moral o jurídico- no ha sido zanjada y permea el debate doctrinal sobre las consecuencias patrimoniales que debieran asignársele al incumplimiento de los deberes personales emanados del matrimonio, más allá de la procedencia del divorcio por culpa. ¿Pueden, además de este divorcio, demandarse por el cónyuge inocente los perjuicios generados por el hecho constitutivo de la causal de divorcio, es decir, la infidelidad?

Este trabajo tiene por objeto presentar la evolución que ha tenido el problema de la procedencia de la responsabilidad civil por incumplimiento del deber de fidelidad en Argentina, con el propósito de confrontar los argumentos doctrinales y jurisprudenciales de las diversas tesis con los fundamentos respectivos acuñados por la dogmática civil chilena. Resulta de la mayor trascendencia para la realidad chilena apreciar el impacto que ha tenido en Argentina el nuevo ccyc en esta materia, sobre todo si, como en mi caso, se aboga por la tesis de la improcedencia de la indemnización de los perjuicios causados por el mero incumplimiento de los deberes personales emanados del matrimonio ${ }^{5}$. En efecto, la experiencia argentina muestra que, a pesar de la reforma legal y de las intenciones que se tuvieron al realizarla, persiste la posibilidad de extender el ámbito de aplicación de la responsabilidad civil en el ámbito de las relaciones personales entre los cónyuges por la vía de identificar otros intereses legítimos vulnerados. Pareciera que la atribución de culpabilidad en el quiebre marital, pese a su eli-

2 Ley 26.994, sancionada el I de octubre de 20I4, promulgada el 7 de octubre de 2014 y publicada en el Boletín Oficial el ro de octubre de 20 I4.

3 Ley 26.6 I8, aprobada en la Cámara de Senadores el i4 de julio de 20 IO.

4 Con fecha 5 de septiembre de 2017 ingresó al Congreso Nacional de Chile el proyecto de ley que modifica diversos cuerpos legales para regular, en igualdad de condiciones, el matrimonio de parejas del mismo sexo (Boletín n. ${ }^{\circ}$ I I.422-07).

5 Turner, S., "Las circunstancias extraordinarias que harían procedente la indemnización de perjuicios entre cónyuges divorciados”, Barría PAREdes, M. (ed.), Estudios de derecho civil XI, Santiago, Thomson Reuters, 20I6, 225-237, 236-237; Íd. "Indemnización de perjuicios a propósito del divorcio por culpa”, en Barría Díaz, R. et al. (eds.), Presente y futuro de la responsabilidad civil, Santiago, Thomson Reuters, $2017,223-225$. 
minación como elemento relevante en el divorcio, se resistiera a salir de escena y aflorara en cuanto requisito de la responsabilidad civil.

\section{El deber de fidelidad entre cónyuges y las consecuencias de su incumplimiento en Argentina}

\section{A. Fidelidad y adulterio en el código civil de Vélez Sarsfield ${ }^{6}$ vigente hasta el I de agosto de 2015}

En el apartado relativo al matrimonio (arts. I 59 ss.), el código civil de Vélez Sarsfield (en adelante, c.c.) contemplaba un capítulo sobre "Derechos y deberes entre los cónyuges" (arts. I 98 a 200). Allí se enumeraban los deberes de fidelidad, asistencia, alimentos y el de convivencia en la misma casa. Estos deberes-derechos formaban parte del orden público familiar por estar consagrados en normas de carácter imperativo, indisponibles para los cónyuges ${ }^{7}$.

La infracción del deber de fidelidad acarreaba el divorcio o la separación personal de los cónyuges, según fuera la acción ejercida por el cónyuge inocente. En efecto, según los hoy derogados artículos 202 n. $^{\circ}$ I y 2 I 4 n. ${ }^{\circ}$ I, el adulterio constituía tanto una causal de separación personal como de divorcio por falta imputable al otro cónyuge ${ }^{8}$.

Las sanciones civiles para el cónyuge infractor del deber de fidelidad consistentes en la separación personal o el divorcio tenían su correlato penal en el delito de adulterio, según el artículo i i 8 c.p., derogado recién en el año i983.

\section{B. Divorcio en el código civil de Vélez Sarsfield vigente hasta el I de agosto de 2015}

En cuanto al divorcio, originalmente en el código civil de Vélez Sarsfield existía solo el divorcio basado en la culpabilidad de alguno de los cónyuges que no disolvía el vínculo matrimonial. Posteriormente, la denominada Ley de Matrimonio Civil de r 888 (Ley 2393) mantuvo el divorcio sin disolución de vínculo que se decretaba en un proceso controvertido y fundado en causales subjetivas por culpa taxativamente enumeradas en la ley.

La Ley I 7.7 I I de i 968 incorporó el divorcio, siempre sin disolución de vínculo, de común acuerdo de los cónyuges. Se trataba de un divorcio causado pero

6 Aprobado por el Congreso argentino en el año I869, entró en vigencia el I de enero de i 87 I.

7 Radcliffe, M., "Las relaciones personales en el matrimonio", en Krasnow (dir.), Manual de derecho de familia, cit., I48.

8 Existían, además, otras dos vías para acceder al divorcio: el divorcio por causales objetivas o divorcio remedio (art. 2 I 4 n. $^{\circ}$ 2) y la conversión de la sentencia de separación personal en sentencia de divorcio cumplidos ciertos supuestos (arts. 202 a 205). 
en cuya resolución no debían constar los hechos aducidos por las partes como "causas graves que hacen moralmente imposible la vida en común".

Recién en I987 la Ley 23.5 I 5 reconoció el divorcio vincular9 ${ }^{9}$ luego de que la Corte Suprema de Justicia de la Nación declarara la inconstitucionalidad de las normas que disponían la indisolubilidad del vínculo matrimonial por ser vulneratorias de derechos constitucionales tales como la igualdad, el derecho a casarse y los derechos de la personalidad. El divorcio regulado tenía causales tanto subjetivas como objetivas. Las primeras eran comunes para el divorcio y la separación personal, con la diferencia de que esta última no disolvía el vínculo matrimonial.

En el Proyecto de código civil de I998, el principio de culpabilidad en materia de divorcio retomó nueva fuerza. En efecto, en su normativa desaparecía el divorcio objetivo y solo se consagraba el divorcio por culpa en virtud de hechos "que constituyan una violación grave o reiterada de los deberes derivados del matrimonio y hagan intolerable el mantenimiento de la vida en común" (arts. 5 I 4 y 527). Entre otras consecuencias de la declaración de culpabilidad del cónyuge, el artículo 525 preveía que este fuera condenado a reparar los daños materiales y morales que la ruptura conyugal había causado al cónyuge inocente, quedando comprendidos tanto aquellos derivados del divorcio en sí mismo como de sus causales ${ }^{\text {IO }}$.

\section{La indemnización de perjuicios por incumplimiento del deber de fidelidad durante la vigencia del código civil de Vélez Sarsfield}

En cuanto a la indemnización de perjuicios asociada a la extinción del vínculo matrimonial, la única disposición expresa era el artículo 225 , relativo a la nulidad matrimonial ${ }^{\text {I }}$. Por el contrario, referida al divorcio sanción no había norma expresa que reconociera el derecho a la reparación civil en favor del cónyuge inocente. Este silencio podía interpretarse en el sentido de una voluntad de no admitirlo o, por el contrario, como una ratificación del principio general consagrado en el artículo I ro9 ${ }^{[\mathrm{r} 2]}$. Fue justamente esta ausencia de norma especial sobre la procedencia o improcedencia de la indemnización de perjuicios frente

9 Excepcionalmente, entre junio de I955 y marzo de I956 rigió la Ley I4.394 que habilitaba a cualquiera de los cónyuges para pedir al juez, transcurrido un año desde la sentencia de divorcio no vincular, la declaración de disolución del matrimonio.

io Barbero, O., "La responsabilidad civil en el derecho de familia (30 años después)", Revista de Furisprudencia Argentina, 2005-IV, octubre-diciembre, I 248.

I I Esta norma había sido introducida al código civil por la Ley de Matrimonio Civil 23.5 I 5 de I987 y prescribía: "El cónyuge de buena fe puede demandar, por indemnización de daños y perjuicios al de mala fe y a los terceros que hubiesen provocado el error, incurrido en dolo o ejercido la violencia".

I 2 Dutro, R., Daños ocasionados en las relaciones de familia, Buenos Aires, Hammurabi, 2006, 86. Esta norma expresaba en su inciso primero: "Todo el que ejecuta un hecho, que por su culpa o 
al incumplimiento del deber matrimonial de guardarse fe la que dio pie a una interesante discusión tanto en la doctrina como en la jurisprudencia argentinas.

La doctrina se mostraba dividida entre aquellos que consideraban procedente la responsabilidad civil frente al incumplimiento de los deberes matrimoniales y aquellos que, en cambio, la consideraban improcedente ${ }^{\mathrm{I}}$. La mayoría aceptaba la indemnización de perjuicios por el daño moral provocado por la causal de divorcio culpable, e incluso por el divorcio en sí mismo ${ }^{\mathrm{I} 4}$. Otros, en cambio, se mostraban contrarios a la procedencia del resarcimiento civil por el mero incumplimiento de los deberes personales ${ }^{\mathrm{I}}$. Existían, además, tesis intermedias ${ }^{\mathrm{I} 6}$ que proponían distinciones sin arraigo expreso en la ley. Partiendo de la base de que el divorcio contempla un sistema de sanciones autónomo (p. ej., desheredamiento del cónyuge culpable, revocación de donaciones en su favor) y descartando de plano que sea resarcible el daño causado por el divorcio en sí mismo, estas tesis intermedias aceptaban la indemnización de perjuicios en el caso de que el daño derive de los hechos que constituyen la causal de divorcio por culpa, pero únicamente cuando "tengan una expansión y gravedad que por sí, al margen de la separación conyugal y de su disolución, entrañen un verdadero daño moral agregado a la persona del cónyuge". Es decir, los hechos que dieron lugar al divorcio debían tener una fuerza dañadora particularmente fuerte para que generaran una indemnización con carácter autónomo. Debían trascender a la mera culpa en el divorcio y, en cambio, constituir ataques personales de manera que el daño causado al otro, al margen del divorcio, no quedase impune ${ }^{17}$.

Por su parte, la jurisprudencia tuvo una evolución interesante en la materia. El primer antecedente de una demanda indemnizatoria por incumplimiento del deber de fidelidad data de i942. La sentencia desechó la indemnización de perjuicios intentada en contra del amante del cónyuge por falta de prueba de

negligencia ocasiona un daño a otro, está obligado a la reparación del perjuicio. Esta obligación es regida por las mismas disposiciones relativas a los delitos del derecho civil”.

I 3 Para una sistematización de la primera doctrina argentina tanto negativa como positiva, cfr. Belluscio, A.; E. Zannoni y A. Kemelmajer de Carlucci, Responsabilidad civil en el derecho de familia, Buenos Aires, Hammurabi, I983, I 7-26. Las tesis denegatoria y permisiva están resumidas en Krasnow, A., "Limitaciones a la reparación del daño en el divorcio. Una tendencia que crece”, Revista de Responsabilidad Civil y Seguros, La Ley, año xiI, n. ${ }^{\circ}$ Io, octubre, 2010, 77-82, y en Kemelmajer de Carlucci, A., "La eliminación del divorcio contencioso en el proyecto de Código Civil y Comercial de la República Argentina y su incidencia en el derecho de daños", en Lepin, C. y D. Vargas (eds.), Santiago, Thomson Reuters, 20 I4, 20 I-208.

I4 Sostenían la postura de la procedencia, p. ej., SAmbrizzi, E., Daños en el derecho de familia, Buenos Aires, La Ley, 200 I, I45; Mosset Iturraspe, J., "Los daños emergentes del divorcio", Revista La Ley, i983-C, 348; Belluscio, A., en Belluscio, Zannoni y Kemelmajer de Carlucci, Responsabilidad civil en el derecho de familia, cit., 26-28.

I 5 Así, p. ej., Borda, G., Tratado de derecho civil. Familia, ı. a ed., t. I, La Ley, 2008, n. ${ }^{\circ} 604$.

i6 Así, p. ej., Cifuentes, S., "El divorcio y la responsabilidad por el daño moral”, La Ley, I99o-B, $805-8$ го.

I 7 Ibíd., pp. 8o8-8го. 
los elementos que configuran la responsabilidad civil, esto es, del hecho ilícito, la imputabilidad y la causalidad entre la infidelidad y el daño ${ }^{18}$. A este caso le seguirían otros en los años I943, I957 y i970[19].

En la década de los ochenta, por el contrario, la jurisprudencia comenzó a reconocer el derecho a la indemnización de perjuicios del cónyuge inocente en caso de adulterio ${ }^{20}$. Se inicia una etapa "dubitativa", según Dutto, en que los fallos no fueron unánimes pues, mientras unos admitían la indemnización en favor del cónyuge inocente, otros le denegaban tal derecho ${ }^{2 \mathrm{I}}$.

En el año 1994, el fallo plenario de la Cámara Nacional de Apelación en lo Civil -convocada con el objeto de establecer la doctrina legal aplicable a la pregunta acerca de "si[,] en nuestro derecho positivo, es susceptible de reparación el daño moral ocasionado por el cónyuge culpable, como consecuencia de los hechos constitutivos de las causales de divorcio"22 - aprobó con carácter de obligatorio para los tribunales nacionales ${ }^{23}$ el principio de la procedencia de la reparación civil en el divorcio por culpa. Se afirmó en esa oportunidad que "en nuestro derecho positivo es susceptible de reparación el daño moral ocasionado por el cónyuge culpable, como consecuencia de los hechos constitutivos de las causales de divorcio".

A partir de este plenario, frente a la pretensión indemnizatoria del cónyuge inocente, el juez debía hacer, al menos, dos distinciones fundamentales. En primer lugar, identificar si se trataba de daños morales o patrimoniales, pues la doctrina obligatoria solo se refería a los primeros y no a los segundos. En segundo lugar, si los daños tenían su causa en los hechos constitutivos de la causal de divorcio por culpa, caso en el que la doctrina aludida resultaba aplicable, o si su causa era el divorcio en $s^{2}{ }^{24}$. En cualquier caso, la doctrina resaltó que según el plenario la concesión de una indemnización de perjuicios en favor del cónyuge

I 8 C. civil 2. ${ }^{\circ}$ cap., JA, I942-II-IO I I, citado por Dutro, Daños ocasionados en las relaciones de familia, cit., $3^{8}$ y 39 .

I9 Para una explicación de estos primeros fallos argentinos, cfr. Belluscio, Zannoni y KemelmaJER de Carlucci, Responsabilidad civil en el derecho de familia, cit., I 5-I 7.

20 Cámara Primera en lo Civil y Comercial de La Plata. Fallo de fecha 7 de abril de i 983 , que condenó a la mujer a reparar el daño moral sufrido por el marido como consecuencia del divorcio decretado por adulterio, injurias graves y abandono de la primera. Citado por Kemelmajer de Carlucci, "La eliminación del divorcio contencioso en el proyecto de Código Civil y Comercial de la República Argentina y su incidencia en el derecho de daños", cit., 202.

2 I Dutro, Daños ocasionados en las relaciones de familia, cit., Iо I.

22 Fallo plenario de 20 de septiembre de i 994, “G., G.G. c/ B. de G., S.”, en Furisprudencia Argentina, t. Iv, Buenos Aires, I 994, 549; La Ley I 994-E, $53^{8}$.

23 La obligatoriedad de los plenarios se fundaba en el artículo 303 del Código Procesal Civil y Comercial de la Nación, derogado por la Ley n. ${ }^{\circ} 26.853$ de 2013.

24 Mizrahi, F., Familia, matrimonio y derecho, 2. a ed., Buenos Aires, Astrea, 2006, 745. 
inocente era facultativa para el juez y no obligatoria ${ }^{25}$, y que el daño moral debía ser analizado con un criterio restrictivo ${ }^{26}$.

El plenario no logró unificar la jurisprudencia posterior porque dejó algunos puntos esenciales sin definir, tales como la suerte de los daños derivados del divorcio en sí mismo y del maño material, además de la eventual compensación de $\operatorname{culpas}^{27}$.

En definitiva, la jurisprudencia mayoritaria anterior a la vigencia del ccyc se mostraba a favor de la procedencia de la reparación civil ${ }^{28}$.

Un análisis de este período de posiciones contrapuestas tanto en la doctrina como en la jurisprudencia arroja una serie de cuestiones debatidas, relacionadas con la pregunta básica sobre la procedencia o improcedencia de la responsabilidad civil frente al incumplimiento del deber de fidelidad:

a. La cuestión acerca del régimen de responsabilidad civil aplicable. La doctrina y la jurisprudencia mayoritarias sostuvieron que los daños intrafamiliares se reclaman según el estatuto de la responsabilidad extracontractual porque provienen de la violación de un deber legal y no del incumplimiento de un contrato 29 .

b. La cuestión acerca de la autonomía de la acción resarcitoria. Se trataba de dilucidar si los cónyuges tenían derecho a demandar una indemnización de perjuicios del otro sin, al mismo tiempo, ejercer una acción de separación personal o divorcio. La doctrina se mostró dividida: unos plantearon que el cónyuge demandante de perjuicios debía haber ejercido previamente una acción de estado de familia pues una sentencia de indemnización de perjuicios decretada durante la convivencia marital constituye un obstáculo para la comunidad de vida, contrariando la especial naturaleza del matrimonio, e incluso prestándose para fraudes en caso de existir seguros comprometidos $3^{\circ}$. Esta posición planteaba que justamente durante el juicio de divorcio surge la legitimación para el cónyuge inocente al probar el daño sufrido. De lo contrario, corresponde presumir el per-

Barbero, O., "La responsabilidad civil en el derecho de familia”, cit., I 25 I.

26 Una década después, y comentando una sentencia emblemática que concedió una indemnización de perjuicios morales cuantiosa fundada en el adulterio de uno de los cónyuges cometido durante la separación, Borda planteaba la necesidad de revisar la doctrina sentada por el plenario, criticando que en el caso no se hubiese probado ni el daño ni su monto y que este se hubiera fijado apreciando "la holgada situación económica del marido". Borda, G, "El daño moral en el matrimonio. La conveniencia de un nuevo plenario", en Revista La Ley, 2005-C, 757-759.

27 Kemelmajer de Carlucci, "La eliminación del divorcio contencioso en el proyecto de Código Civil y Comercial de la República Argentina y su incidencia en el derecho de daños”, cit., 203.

28 Para un listado de sentencias en este sentido, cfr. JALIL, J., "Daños derivados del divorcio y presupuestos para la procedencia de la responsabilidad civil”, en Revista Familia y Patrimonio, año 3, n. ${ }^{\text {o } ~ I, ~ f e b r e r o, ~} 20$ I I, 30, nota 94.

29 Dutto, Daños ocasionados en las relaciones de familia, cit., 52; Barbero, "La responsabilidad civil en el derecho de familia", cit., I 246.

30 Fleitas Ortiz de Rozas, A. y E. Roveda, Manual de derecho de familia, $3 .{ }^{a}$ ed., Buenos Aires, Abeledo Perrot, 20 I I, I83. 
dón de la ofensa en que incurrió el cónyuge culpable. Es decir, la acción resarcitoria es accesoria de la acción de divorcio y debe ejercerse conjuntamente con ella o con posterioridad. Como consecuencia de lo anterior, los únicos titulares de la acción indemnizatoria son las partes en el juicio de divorcio, y dicha acción es intransmisible e intransferible ${ }^{3}$. Por el contrario, defendiendo la autonomía de la acción indemnizatoria y a propósito del artículo 525 del Proyecto de código civil de I998, se criticó la exigencia consistente en que los perjuicios fueren reclamados en el mismo juicio de separación o divorcio, pues excluía la posibilidad de que surgieran daños reparables en el propio juicio ${ }^{32}$.

c. La cuestión acerca de la procedencia de la acción resarcitoria en un divorcio sin culpa. La doctrina se mostraba dividida. Algunos autores sostuvieron que el divorcio objetivo no da derecho a indemnización de perjuicios ${ }^{33}$. Otros, en cambio, sostuvieron que si en el caso de divorcio por separación personal sin voluntad de unirse (art. 204 c.c.), en el que no se atribuía culpa, uno de los cónyuges alega y prueba no haber dado causa a la separación, podría también reclamar el resarcimiento de los daños y perjuicios 34 .

d. Sobre la eventualidad de los daños en el divorcio por culpa. La doctrina se encargó de remarcar que las antiguas causales de divorcio por culpa (arts. 202 y 204 c.c.) no pueden constituir por sí mismas una causa para lograr una reparación ${ }^{35}$. En un sistema de divorcio sanción los hechos constitutivos de la casual no necesariamente producen un daño reparable. El juicio de divorcio denota la existencia de una crisis en la pareja, pero ella no siempre implica que uno de los cónyuges sea víctima de un daño indemnizable ${ }^{6}$. En definitiva, el cónyuge

3 I Dutto, Daños ocasionados en las relaciones de familia, cit., 52; BARbero, "La responsabilidad civil en el derecho de familia”, cit., 75-78 y 97-98.

32 Cfr. Sambrizzi, E., Daños en el derecho de familia, Buenos Aires, La Ley, 200 I, i68. Por el contrario, Fleitas Ortiz de Rozas y Roveda niegan toda posibilidad de reparación de los daños resultantes del divorcio mismo. Cfr. Fleitas Ortiz de Rozas y Roveda, Manual de derecho de familia, cit., I87. El artículo 525 mencionado establecía: "Daños. Si la separación se decreta por culpa exclusiva de uno de los cónyuges, éste puede ser condenado a reparar los daños materiales y morales que la separación causó al cónyuge inocente. La demanda por daños sólo es procedente en el mismo proceso de separación.

"Los daños provenientes de los hechos ilícitos que constituyen causales de separación son indemnizables.

"En todos los casos se aplica el artículo r686". Por su parte, esta última disposición indicaba al respecto: "Aplicación. Sin perjuicio de disposiciones especiales en los siguientes casos, sólo hay responsabilidad si se obra por dolo o culpa grave: a) Si el daño, en los casos en que no está justificado, se produce en el ámbito de las relaciones de familia”.

33 Dutro, Daños ocasionados en las relaciones de familia, cit., 52; BARbero, "La responsabilidad civil en el derecho de familia", cit., 99.

34 Medina, G., Daños en el derecho de familia, Santa Fe, Rubinzal-Culzoni, 2002, 83.

35 Borda, "El daño moral en el matrimonio. La conveniencia de un nuevo plenario", cit., 757.

36 Krasnow, "Limitaciones a la reparación del daño en el divorcio. Una tendencia que crece", cit., 87 y 88 . 
inocente no siempre tendrá derecho a una indemnización de perjuicios como un efecto inmediato y necesario del divorcio 37.

e. Sobre la entidad del daño sufrido por el cónyuge inocente. La doctrina puso de relieve que la indemnización de perjuicios debía fundarse en daños de una cierta gravedad. Se aludió a que los hechos constitutivos de la causal de divorcio por culpa acogida por la sentencia respectiva debían revestir una gravedad tal que justificara el resarcimiento ${ }^{3}{ }^{8}$. En este mismo sentido, hubo intentos por delimitar la reparación civil reforzando el grado de culpa del cónyuge infractor. Así, en el Proyecto de código civil de I998, los artículos 525 y 529 acogían la indemnización de perjuicios por los daños materiales y morales sufridos por el cónyuge inocente cometidos con dolo o culpa grave. En este proyecto, entonces, se ponía freno a la acción indemnizatoria por dos vías: por una parte, a través de la exigencia de dolo o culpa grave en la infracción del cónyuge que causaba el daño; por otra, a través del concepto de "daño justificado" 39 . También se limitaron los daños indemnizables distinguiendo el momento en que estos se producían. La reparación de los daños derivados de la vida cotidiana no fue abordada por la doctrina, la cual se concentró en aquellos asociados al término del matrimonio por divorcio ${ }^{\circ}$.

\section{El deber de fidelidad en el código civil y comercial y las consecuencias de su incumplimiento}

\section{A. El deber de fidelidad en el código civil y comercial}

Iniciando el libro segundo, referido a las "Relaciones de Familia", el título I sobre "Matrimonio" (arts. 4OI ss.) mantiene un capítulo referido a los "Derechos y deberes de los cónyuges" (arts. 43 I a 434). Señala el artículo 43 I: "Asistencia. Los esposos se comprometen a desarrollar un proyecto de vida en común basado en la cooperación, la convivencia y el deber moral de fidelidad. Deben prestarse asistencia mutua". A continuación se consagra el deber de alimentos entre cónyuges durante la vida en común o la separación de hecho, y con posterioridad al divorcio en ciertos supuestos.

Por consiguiente, según la nueva normativa, podrían diferenciarse los deberes matrimoniales que constituyen una verdadera obligación jurídica de aquellos que tienen un contenido exclusivamente moral. Los primeros son los deberes de

37 JALIL, "Daños derivados del divorcio y presupuestos para la procedencia de la responsabilidad civil", cit., I4.

38 Dutto, Daños ocasionados en las relaciones de familia, cit., 52; BARBEro, "La responsabilidad civil en el derecho de familia", cit., 96 .

39 Barbero, "La responsabilidad civil en el derecho de familia", cit., I 248.

40 Fleitas Ortiz de Rozas y Roveda, Manual de derecho de familia, cit., i 82. 
asistencia y de alimentos. Por el contrario, los de cooperación, cohabitación y fidelidad, si bien forman parte del "proyecto de vida en común” acordado por los cónyuges y tienen un alto valor axiológico, no pueden exigirse compulsivamente y su incumplimiento no genera consecuencias jurídicas ${ }^{4}$. Siendo, entonces, la fidelidad un mero deber moral, fruto del compromiso de los cónyuges de no mantener relaciones sexuales extramatrimoniales ${ }^{42}$, el adulterio ya no es antijurídico y por consiguiente ya no resulta procedente la indemnización de perjuicios en contra del cónyuge infiel ${ }^{43}$. Subsiste como valor ético o moral en la vida matrimonial, sin perjuicio de que desaparece de la órbita jurídica44.

\section{B. El divorcio en el código civil y comercial}

En cuanto al divorcio, el ccyc consagró un sistema único de divorcio incausado, desapareciendo, por consiguiente, las causales de divorcio por culpa. Los "Fundamentos" del proyecto de reforma advierten acerca de las perniciosas consecuencias del divorcio contencioso, tanto para los cónyuges como para sus familias 45 . La consagración, en cambio, de un divorcio sin atribución de culpas propende al respeto de derechos fundamentales tales como el derecho a la libertad, a la igualdad, a la vida familiar de manera pacífica y el derecho de los hijos a mantener relaciones con ambos padres tras la ruptura matrimonial. El foco de la

4I Art. 435, Fundamentos (segundo párrafo): "Otra modificación sustancial es la supresión de las causales subjetivas de divorcio. La experiencia judicial ha demostrado el alto nivel de destrucción y desgaste emocional al que se someten los cónyuges y sus familias cuando se opta por el divorcio contencioso. El valor pedagógico de la ley es conocido; el Anteproyecto pretende contribuir a la pacificación de las relaciones sociales en la ruptura matrimonial. La eliminación de las causales subjetivas es una manera de colaborar a superar la ruptura matrimonial de la manera menos dolorosa posible. De este modo, y de conformidad con la línea legislativa que adoptan varios países en sus reformas más recientes, se prevé un único sistema de divorcio remedio". Zannoni, E. et al. (revisores), Código Civil y Comercial. Concordado con el régimen derogado y referenciado con legislación vigente, 2. " reimp., Buenos Aires, Astrea, 2015 , art. 43 I, "Fundamentos".

42 Kemelmajer, A.; N. Lloveras y F. Faraoni, "Matrimonio", en Kemelmajer de Carlucci, A.; M. Herrera y N. Lloveras, N. (dirs.), Tratado de derecho de familia, t. v-A, r. a ed. revisada, Santa Fe, Rubinzal-Culzoni, 2016, 31-32.

43 Marcellino, L., “¿Son resarcibles las consecuencias no patrimoniales derivadas de la infidelidad de uno de los cónyuges en el Cccn?", en Revista de Derecho de Familia y de las Personas, La Ley, año viI, n. ${ }^{\circ}$ I I, diciembre, 20I 5, 70-7I; Radcliffe, M., "Las relaciones personales en el matrimonio", en Krasnow (dir.), Manual de derecho de familia, cit., I 49. Molina de Juan plantea que la excepción a la improcedencia de la indemnización de perjuicios podría darse cuando la conducta reprochada a uno de los cónyuges afecta la condición de persona del cónyuge víctima, independientemente del vínculo matrimonial que une a ambos, tal como en el caso de violencia de género o atentados en contra del honor o intimidad; cfr. Molina de Juan, M., "Derechos y deberes de los cónyuges", en Kemelmajer de Carlucci, A.; M. Herrera y N. Lloveras (dirs.), Tratado de derecho de familia, t. I, Santa Fe, Rubinzal-Culzoni, 20 I4, 257.

44 Ibíd., 243.

45 Zannoni et al. (revisores), Código Civil y Comercial. Concordado con el régimen derogado y referenciado con legislación vigente, cit., I $5 \mathrm{I}$. 
normativa legal está en los efectos y no en las causas del divorcio, lo que propende a la resolución de la crisis matrimonial hacia el futuro ${ }^{4}$. Prueba de ello es que la presentación de la propuesta o convenio regulador condiciona la viabilidad de la demanda de divorcio 47.

Este cambio radical en el divorcio, sobre todo considerando que en el Proyecto de 1998 el principio de culpabilidad recobraba nueva fuerza, fue antecedido por una corriente doctrinal y jurisprudencial que bajo la vigencia del antiguo código había interpretado de manera restrictiva las distintas causales subjetivas, logrando una aplicación más flexible de las mismas ${ }^{4}$. En relación con el adulterio, por ejemplo, algunos fallos habían establecido que la no existencia de vulneración del deber de fidelidad durante la separación de los cónyuges, y así lo había corroborado parte de la doctrina 49 .

\section{Indemnización de perjuicios por infracción del deber moral de fidelidad}

De acuerdo con la inspiración del ccyc antes aludida, resulta que deben distinguirse dos ámbitos en que un cónyuge podría sufrir un daño causado por el otro: el daño que se le produce en tanto persona, independientemente de la existencia del matrimonio, y aquel que soporta en cuanto cónyuge porque medió una infracción de un deber propio del matrimonio. Mientras en el primero resulta irrelevante que el autor del daño sea cónyuge de la víctima, en el segundo este hecho constituye un presupuesto para la ocurrencia del daño. Ejemplo del primer tipo de daño sería la lesión física causada por un cónyuge al otro, que se traducirá en la obligación de indemnizar el daño emergente, el lucro cesante y el daño moral que se logre acreditar. En efecto, tratándose de un hecho antijurídico que causa daño, el cónyuge victimario deberá resarcir los perjuicios sufridos por el cónyuge víctima, porque el matrimonio no anula ni disminuye los derechos fundamentales de que es titular cada cónyuge. El matrimonio no es causal de justificación ni ampara un derecho a dañar.

En cambio, el daño sufrido por un cónyuge en su condición de tal se produce por el incumplimiento de un deber surgido del vínculo matrimonial mismo. De

46 Molina de Juan, M., "Disolución del matrimonio", en Kemelmajer de Carlucci, A.; M. Herrera y N. Lloveras (dirs.), Tratado de derecho de familia, t. I, Santa Fe, Rubinzal-Culzoni, 20 I4, 35 y y 357. Kemelmajer de Carlucci, A., "Lineamientos generales del derecho de familia en el proyecto de Código Civil y Comercial unificado. Por qué no al maquillaje", Revista de Derecho Privado y Comunitario, Rubinzal-Culzoni, 20 2-2, I, 309-3 10.

47 Parodi, M., "La disolución del matrimonio y sus causales", en Krasnow (dir.), Manual de derecho de familia, cit., $\mathrm{I} 7 \mathrm{I}$.

48 Ibíd., I65.

49 Sambrizzi, E., "Subsistencia del deber de fidelidad durante la separación de hecho y daño moral derivado de la causal de adulterio", La Ley, 2005-C, 199-208. 
allí que víctima y victimario necesariamente deban ser los cónyuges. Es lo que ocurre con la infracción del deber de fidelidad. Dado que según el ccyc la infidelidad de alguno de los cónyuges constituye una infracción de un deber moral emanado del matrimonio, su consecuencia queda entregada a la esfera privada de los cónyuges. Ellos podrán perdonarla o no, pero en ningún caso dará lugar a una indemnización de los perjuicios sufridos. La única solución ante el incumplimiento del deber moral es solicitar el divorcio, siendo irrelevantes sus motivos ${ }^{5}$.

Descartada la procedencia del sistema general de responsabilidad civil por incumplimiento de un deber matrimonial queda abierta, en todo caso, la vía de reclamación por el daño sufrido en cuanto persona, cuya suerte quedará condicionada a la prueba del daño, independientemente de su condición de cónyuge.

En cuanto a la justificación del cambio en la calificación legal del deber de fidelidad -desde una obligación jurídica a un deber ético-, la doctrina argentina ha propuesto distintos fundamentos.

Por una parte, que se pretendió alcanzar un consenso entre los autores destinado a fortalecer el tránsito desde el antiguo sistema de divorcio por culpa hacia uno incausado. Se trató, desde este punto de vista, de un "concepto intermedio" para lograr la aceptación del cambio ${ }^{5}$.

Por otra, que la modificación responde a un cambio de principios. La concepción filosófica del ccyc se aparta del concepto natural de matrimonio, íntimamente influenciado por convicciones religiosas y, en cambio, acoge un modelo secular del mismo, fomentando la libertad de intimidad, de conciencia y religiosa propias de una sociedad democrática. En ese contexto, la eliminación del deber jurídico de fidelidad devuelve a los cónyuges el poder de decisión sobre las relaciones internas del matrimonio, evitando una injerencia arbitraria del derecho en la vida de las personas. Son los propios cónyuges los que definen la fidelidad según el proyecto de vida conjunto que hayan asumido. Se abre para ellos un espacio de elección sobre las modalidades en que se ejercitará el deber de fidelidad del matrimonio. De allí que se hable de la contractualización del derecho de familia ${ }^{5}$. Se evita, además, la cuestión acerca del cumplimiento forzado del deber de fidelidad que es axiológicamente disvalioso, contrario a la dignidad humana y materialmente imposible 53 .

También se ha sostenido que la tutela de la familia en el ccyc está presidida por el valor de la solidaridad que constituye una verdadera cláusula general del

50 Kemelmajer de Carlucci, A.; N. Lloveras y F. Faraoni, "Matrimonio", en Kemelmajer de Carlucci, A.; M. Herrera y N. Lloveras (dirs.), Tratado de derecho de familia, t. v-A, r. ${ }^{a}$ ed. revisada, Santa Fe, Rubinzal-Culzoni, 2016, 32-33.

5 I Chechile, A., "El divorcio en el proyecto de Código Civil y Comercial de la Nación”, en Revista de Derecho de Familia, n. ${ }^{\circ}$ 57, I69.

52 Kemelmajer, Lloveras y Faraoni, "Matrimonio", cit., 30.

53 Molina de Juan, "Derechos y deberes de los cónyuges", cit., 252-254. 
ordenamiento jurídico familiar. Una de sus manifestaciones se presenta a propósito de los efectos del matrimonio. La consagración en el artículo 43 I ccyc del deber de asistencia entre los cónyuges como único deber jurídico que los vincula durante el matrimonio refleja justamente este valor fundamental. Frente a él, el deber de fidelidad, si bien conserva su valor moral, carece de consecuencias pecuniarias si se incumple ${ }^{54}$. En este nuevo escenario, el único deber jurídico cuyo incumplimiento podría satisfacer el requisito de la responsabilidad extracontractual consistente en la antijuridicidad, y, por ende, acarrear el deber de indemnizar los perjuicios causados, sería el deber de asistencia recíproca 55 .

El deber jurídico de asistencia entre los cónyuges tiene un contenido tanto moral como patrimonial. En su faz personal, se identifica con el apoyo afectivo, la ayuda espiritual, el respeto recíproco, la solidaridad afectiva, los cuidados materiales y espirituales que los cónyuges deben dispensarse recíprocamente. Por otra parte, la faz patrimonial del deber está constituida por los alimentos fundados en la existencia del vínculo matrimonial $5^{6}$.

La eliminación del deber jurídico de fidelidad ha encontrado cierta oposición en la doctrina. Así, Álvarez sostiene que existiría un verdadero derecho al daño matrimonial y que la pretendida disociación de la responsabilidad civil con respecto al matrimonio finalmente incita a los malos comportamientos por parte de los cónyuges ${ }^{57}$.

Por su parte, Medina ha defendido la tesis de que bajo el nuevo estatuto legal aún cabe seguir hablando de la responsabilidad por los daños derivados del divorcio, a pesar de que en el nuevo sistema no se juzgan las culpas, el divorcio es incausado y los deberes personales de los cónyuges se encuentran limitados. Sostiene que en ese contexto la responsabilidad civil es procedente en la medida que se den sus presupuestos, porque los daños que se producen en el interior de la familia son más graves dado que el sujeto que los causa tiene una especial obligación de cuidado respecto de la víctima y no una mera obligación de no dañar. Según la autora, el hecho de que la fidelidad se califique de deber moral no obsta para que exista un daño indemnizable generado por la lesión de un interés no reprobado por el ordenamiento jurídico, según el artículo $1737 \mathrm{Ccyc}^{58}$. Además, argumenta que existe una conducta antijurídica, de acuerdo con el ar-

54 Kemelmajer de Carlucci, "Lineamientos generales del derecho de familia en el proyecto de Código Civil y Comercial Unificado", cit., 307.

55 Kemelmajer de Carlucci, "La eliminación del divorcio contencioso en el proyecto de Código Civil y Comercial de la República Argentina y su incidencia en el derecho de daños”, cit., 2 I9.

56 Kemelmajer, Lloveras y Faraoni, "Matrimonio", cit., 33-34.

57 Álvarez, O., "Código Civil y Comercial y daño moral con motivo del divorcio vincular", en Revista La Ley 201 5-C, 1083.

58 "Art. I 737. Concepto de daño. Hay daño cuando se lesiona un derecho o un interés no reprobado por el ordenamiento jurídico, que tenga por objeto la persona, el patrimonio, o un derecho de incidencia colectiva”. 
tículo I 7 I $7^{[59]}$, pues solo el ejercicio regular de un derecho y no su abuso puede considerarse justificado. Probados, entonces, los elementos de la responsabilidad civil en un juicio independiente del de divorcio, habrá lugar a la indemnización de los perjuicios en favor del cónyuge inocente ${ }^{60}$.

También Asar y Ossola manifiestan su desacuerdo frente a la tesis de que la eliminación del divorcio por culpa conllevaría necesariamente la improcedencia de la acción indemnizatoria en caso de vulneración de un deber matrimonial, aun cuando este fuere meramente moral. Es decir, la inexistencia de una declaración de culpabilidad del cónyuge infiel en sede de divorcio no sería inconveniente para perseguir su eventual responsabilidad civil ${ }^{61}$. Ella procederá en la medida que la infracción del deber de fidelidad cause daño en el otro cónyuge y exista relación de causalidad adecuada y factor de atribución. En cuanto al requisito de la antijuridicidad del hecho generador de responsabilidad civil, este se verificaría aun cuando el deber incumplido tenga un carácter moral, pues "lo inmoral como marco regulador de la ilicitud constituye una fuente directa de la obligación de resarcir el daño ocasionado" ${ }^{2}, \mathrm{y}$, en cualquier caso, habría antijuridicidad porque no concurre en favor del cónyuge infiel alguna causa de justificación específica que lo habilite para actuar ocasionando el daño.

En relación con la jurisprudencia, a partir de la vigencia del ccyc y, por ende, de la reconfiguración del deber de fidelidad entre los cónyuges y del divorcio, se han fallado casos interesantes, entre otros, los siguientes.

En una sentencia de la Cámara de Apelaciones, Sala I, de Gualeguaychú, Entre Ríos, del año 20I6[63], la mujer demandó al marido la indemnización de perjuicios por los daños morales causados por los hechos constitutivos de la causal de divorcio -la infidelidad-, sin obtener resultado favorable en primera instancia. Argumentó el juez que la prueba rendida por la mujer no había logrado establecer la relación de causalidad necesaria entre el hecho y el daño. La mujer apeló la sentencia, objetando que no se hubiera considerado la prueba rendida en el juicio de divorcio anterior, en el que se probó que el marido tuvo un hijo extramatrimonial durante la separación. Según ella, la ponderación de los hechos probados para configurar la causal de divorcio por culpa era imprescindible para dar por ciertos los daños morales sufridos.

La apelación fue rechazada. En este caso, la Corte declaró aplicable el código civil antiguo pues era el vigente en el momento de ocurrencia de los hechos.

59 "Art. I 7 I 7. Antijuridicidad. Cualquier acción u omisión que causa un daño a otro es antijurídica si no está justificada".

6o Medina, G., "Daños en el derecho de familia en el Código Civil y Comercial", en Revista de Responsabilidad Civil y Seguros, La Ley, año xviı, n. ${ }^{\circ}$ 4, abril, 2005, 289-29I.

6 I Azar, A. y F. Ossola, "Principio de indemnidad, deber moral de fidelidad entre cónyuges y resarcimiento de daños", La Ley I4/I 2/2016, 5, cita online: AR/Doc/3787/20I6

62 Ibíd., 6.

63 Sentencia de fecha 4 de marzo de 20r6. Rubinzal Online Cita: RC J I980/r6. 
Luego de aclarar que la prueba en el juicio de divorcio anterior había estado enfocada en probar las causales subjetivas de divorcio aplicables -esto es, infidelidad e injurias graves-, aclaró que para reconocer el derecho a indemnización de perjuicios, en cambio, faltaba, por parte del marido, el "inequívoco propósito de dañar la integridad espiritual, prestigio o actividad laboral de la accionante, más allá claro está del lógico duelo que produce el divorcio en sí mismo por el fracaso de no poder concretar proyectos comunes". Agregó que "no todo disgusto, desagrado o contrariedad, sufrido como consecuencia del divorcio se enmarca en el concepto jurídico de daño moral, pues para que el mismo se configure, debe existir una ofensa fuera de lo común, ya que en caso contrario se llegaría al exceso de sostener que toda causa culpable de la ruptura del vínculo matrimonial es fuente de resarcimiento autónomo".

En una sentencia de la Cámara Nacional de Apelaciones en lo Civil de Buenos Aires, Sala H, de $2016^{[64]}$, el tribunal de primera instancia acogió el divorcio incausado demandado por el marido y, en cambio, rechazó la demanda reconvencional de la mujer de indemnización de perjuicios por el daño moral y psicológico sufrido como consecuencia de la violencia acaecida durante el último tiempo del matrimonio y durante la separación. El fundamento de tal rechazo fue que el ccyc no confería el necesario "respaldo normativo" para acoger una indemnización de perjuicios en caso de divorcio ${ }^{65}$. Apelada la sentencia por la mujer, esta alegó que las reglas generales sobre responsabilidad civil del nuevo ccyc, artículos 1737 y siguiente, resultaban aplicables al caso, constituyendo el fundamento normativo para acoger la indemnización de perjuicios.

En segunda instancia, la Cámara confirmó el divorcio y revocó la sentencia en cuanto no concedía la indemnización de perjuicios en favor de la mujer. El tribunal de alzada recordó la intención del ccyc en orden a suprimir las indemnizaciones de perjuicios basadas en la infracción de los deberes personales del matrimonio pero, al mismo tiempo, indicó que en el caso no se trataba de un incumplimiento de ese tipo sino de una situación en que "se dan los presupuestos de responsabilidad civil, como el ataque al honor, la intimidad, dignidad, integridad física o psíquica", y por consiguiente, esos daños deberían ser reparados. "Entender lo contrario sería admitir un campo de inmunidad para el sujeto dañador, o en el peor de los casos, que se encuentra configurada una renuncia anticipada a la posibilidad de reclamar la reparación de los daños sufridos por quien resulte víctima de hechos lesivos ocasionados en el ámbito familiar”. Aplicando,

64 Sentencia de fecha 2 I de abril de 20r6. Rubinzal Online Cita: RC J 3049/ı6.

65 En un comentario del fallo, Ortiz critica que el tribunal de primera instancia haya considerado que carecía de apoyo normativo, pues si bien el ccyc no estaba vigente al momento de la ocurrencia de los hechos, sí lo estaban la Ley 26.485 sobre Violencia contra la Mujer, en el ámbito nacional, y la Convención para Prevenir, Sancionar y Erradicar la Violencia contra la Mujer, en el internacional. Cfr. Ortiz, D., "Crónica de un comienzo anunciado: daños en violencia familiar. Comentario al fallo 's. J. J. c/ G. M. M.'”, Microjuris.com, cita: MJ-Doc-9982-AR I MJD9982. 
entonces, el artículo I7I6 ccyc, referido al deber de reparación ${ }^{66}$, y el artículo I 7 I 7 ccyc, que reconoce la antijuridicidad como el presupuesto configurativo de la responsabilidad civil, concluyó que "el derecho de daños debe actuar como un medio idóneo que brinde respuestas adecuadas, conforme a un resarcimiento justo, a los menoscabos sufridos por una víctima en su esfera familiar, atendiendo particularmente a las circunstancias del caso".

En definitiva, el tribunal de alzada revocó la sentencia de primera instancia y, aplicando el código civil de Vélez Sarsfield dado que era el derecho vigente en el momento de los hechos antijurídicos, calificó el caso como prototípico de responsabilidad por daños que tuvo su origen en la violencia doméstica "que no puede ser tolerada ni permitida por la sociedad". Cuando estas situaciones "son ventiladas ante los Estrados Judiciales los jueces no podemos permanecer pasivos como convidados de piedra, debiendo llamar a la reflexión social sobre esta cuestión, poniendo especial énfasis en su gravedad, y [en] las posibles derivaciones que pueden tener cuando no se pone límite a ese desenfreno". A este propósito citó, además, las conclusiones de las xxv Jornadas Nacionales de Bahía Blanca de $2015^{[67]}$, donde se aprobó por unanimidad declarar que "[e]l derecho de familia no constituye un ámbito ajeno a la aplicación de las normas y principios de la responsabilidad civil, no obstante la necesaria compatibilización de estos con la especificidad de los vínculos familiares", y que "constituyen supuestos de resarcimiento entre cónyuges los daños provocados por violencia familiar y de género". Reforzando el argumento, el juez Kiper añadió que en el caso era irrelevante que la víctima del hecho antijurídico hubiese sido el cónyuge o conviviente del obligado a la reparación, o simplemente un tercero”.

En una sentencia de la Cámara de Apelaciones en lo Civil, Comercial, Laboral y de Minería de la segunda circunscripción judicial de General Pico, La Pampa, de $2016^{[68]}$, la mujer, quien había sido descubierta por el marido saliendo de un hotel con su amante, produciéndose un incidente entre ambos que tuvo difusión en diarios locales y sitios de internet, presentó la demanda de divorcio alegando la culpabilidad de su marido por la causal de injurias graves, a lo que este contestó con demanda de reconvención de divorcio culpable por causa de adulterio, tentativa contra su vida, injurias graves y abandono voluntario y malicioso de parte de su esposa, además de demandar la indemnización del daño moral sufrido. En primera instancia, el juez rechazó la demanda de la mujer y

66 “Art. i 7 r6. Deber de reparar. La violación del deber de no dañar a otro, o el incumplimiento de una obligación, da lugar a la reparación del daño causado, conforme las disposiciones de este Código".

67 xxv Jornadas Nacionales de Derecho Civil, Universidad de Bahía Blanca, conclusiones Comisión $3 .^{\mathrm{a}}$. Disponible con ediciones anteriores en: http://jornadasderechocivil.jursoc.unlp.edu. ar/ediciones-anteriores/

68 Sentencia de fecha I4 de diciembre de 20r6, disponible en: www.elmercurio.com/Documentos/Legal/20 I 7/06/07/20 I 70607 I64556.pdf [consultado el i 5 de octubre de 201 7 ]. 
la reconvencional del marido, decretando el divorcio sin culpa del artículo 2 I 4 inciso $2 .^{\circ}$ c.c. Además, desechó la demanda indemnizatoria del marido. Ambas partes apelaron del fallo.

Frente al problema de la aplicación del ccyc en el tiempo, la Corte señaló que corresponde resolver el caso puntual bajo sus normas, pues en el momento de entrar en vigencia dicho código se encontraba aun en tramitación, sin sentencia definitiva. Por lo tanto, deviene "inoficioso cualquier pronunciamiento sobre los agravios referidos a las causales invocadas por cada uno de los apelantes para atribuir al otro la culpa del divorcio". En lo resolutivo, entonces, acoge el divorcio incausado de acuerdo con el artículo 437 ccyc.

En relación con la indemnización del daño moral, el tribunal de segunda instancia acogió la apelación del marido y reconoció su derecho a ella. Luego de un extenso resumen de las dos posiciones doctrinarias (la que afirma la procedencia de la indemnización de perjuicios al caso de adulterio cuando se cumplen todos los requisitos de la responsabilidad civil reconocidos por el ccyc, pese a que el deber de fidelidad según la nueva normativa es moral y no jurídico, y la que deniega tal procedencia por considerar que actualmente la infidelidad no es un hecho antijurídico), el fallo de mayoría se inclinó por la tesis afirmativa.

Según la argumentación del fallo, la conducta ilícita de la mujer "no está dada por el hecho del divorcio, sino por el obrar nocivo para el otro cónyuge, habiendo un factor subjetivo de responsabilidad, el cual debe ser claramente acreditado". Tampoco la infidelidad por sí sola "genera in re ipsa un daño moral, ni tampoco se lo presume". Por otra parte, la calificación del deber de fidelidad como deber moral, según el artículo 43 I ccyc, no obsta para que su infracción haya afectado un interés relevante que se manifiesta en el derecho a la dignidad, la armonía familiar, la integridad psíquica y moral, "que son derechos tutelados por el ordenamiento jurídico, por lo cual son dignos de amparo legal y merecen ser resarcidos". Al contrario de lo que sucedía en el código civil de Vélez Sarsfield, el daño injusto no presupone un deber legal preestablecido "sino que surge de cotejar el ordenamiento jurídico entendido en su totalidad (especialmente tratados internacionales y Constitución Nacional), para determinar si existe un interés que puede verse afectado en el caso concreto, el cual en la medida que merezca tutela jurídica deberá ser indemnizado".

Dando por cumplidos los presupuestos de la responsabilidad civil en el caso, la Corte cuantificó el daño sufrido por la víctima. $\mathrm{Al}$ respecto, consideró, por una parte, que se trataba de un matrimonio de larga duración (25 años) y "desgastado", en cuyo contexto la infidelidad podría aparecer aminorada en sus efectos. Sin embargo, el caso "fue traumático a punto tal que el reconviniente estuvo a punto de suicidarse. Además de ello la repercusión de los medios de comunicación del hecho impactó negativamente en un profesional conocido en la ciudad, como es $\mathrm{C}$, habiendo generado un menoscabo importante en su persona, atendible a la hora de cuantificar el daño". 


\section{La experiencia argentina confrontada con la realidad chilena}

La pregunta acerca de las repercusiones del adulterio como hecho constitutivo de la causal de divorcio por culpa en el ámbito de la responsabilidad civil también se ha ganado un lugar en el derecho civil chileno. Desde que en el año $2004^{[69]} \mathrm{se}$ consagrara el divorcio como causal de terminación del matrimonio, tanto aquel fundado en el cese de la convivencia como el basado en la imputación de una causal culpable, en la doctrina nacional pueden distinguirse las dos posturas extremas ya enunciadas, esto es, la de la procedencia y la de la improcedencia de la indemnización de perjuicios por los hechos constitutivos de la causal de divorcio culpable, además de una tesis intermedia ${ }^{7}$.

Lo interesante es que la confrontación de los argumentos invocados en ambos derechos para defender una u otra tesis arroja la conclusión de una casi total coincidencia entre ellos. En este sentido, resulta ilustrativo que, en la explicación exhaustiva de la tesis positiva y negativa abordada por Otarola, la doctrina argentina y chilena -además de otras, por supuesto- sirvan conjunta e indistintamente de apoyo para cualquiera de las posturas ${ }^{71}$.

Así, la especialidad del derecho de familia, el principio non bis in idem, el carácter ético del derecho de familia, la inmunidad familiar, la preservación de la estabilidad y la paz familiar y el correlativo desincentivo a la litigiosidad basada en la culpa, como fundamentos de la tesis negativa, y la invocación de la noción de familia moderna en que no cabe el reconocimiento de privilegios tales como una cierta inmunidad familiar, la prevalencia del principio supralegal de prohibición de dañar a otro, la necesaria interpretación del derecho de familia como parte integrante del derecho civil y la asunción de la función reparadora del derecho de daños, como argumentos de la tesis positiva, se repiten en Chile y Argentina ${ }^{72}$.

En cuanto a la jurisprudencia chilena, el fallo de la Corte de Apelaciones de Santiago de 2009 es un buen ejemplo de la manera en que ella ha recogido los

69 Ley 19.947, que establece una nueva ley de matrimonio civil, publicada con fecha I 7 de mayo de 2004 .

70 Para un completo panorama de las posturas asumidas por la doctrina chilena, cfr. TAPIA RodríGuez, M., "Divorcio y responsabilidad civil en el derecho chileno", en Revista de Derecho de la Universidad de Concepción, n. ${ }^{\circ}$ 239, año LxxxiV, enero-junio, 2016, I66-г67.

7 I Otarola Espinoza, Y., Incumplimiento de los deberes matrimoniales y responsabilidad civil, Madrid, Reus, 2016, 33-139.

72 Así ocurre, por ejemplo, si se contrastan los resúmenes de argumentos que presentan Lepin, por una parte, y Tanzi y Papillú, por otra. Lepin Molina, C., "Responsabilidad civil en las relaciones de familia", en Lepin Molina, C. (dir.), en Responsabilidad civil y familia, Santiago, Thomson Reuters, 20I4, 4I3-424. Tanzi, S.; Papillú, J., "Daños y perjuicios derivados del divorcio. Doctrina y jurisprudencia en Argentina", Revista Chilena de Derecho Privado, n. ${ }^{\circ}$ I6, julio, 20II, I38-I40, disponible en: http://www.scielo.cl/scielo.php?script=sci_arttext\&pid $=$ So7 I 8-8072201 1000100004 [consultado el I 5 de octubre de 2017]. 
argumentos doctrinales ${ }^{73}$. En dicha sentencia se desarrollan, a partir del considerando quinto, los argumentos que apoyan la tesis de la improcedencia de la indemnización de perjuicios para el caso de quebrantamiento del deber de fidelidad: el carácter de orden público del derecho de familia y su especialidad, y el contenido ético-moral de los deberes personales emanados del matrimonio, justifican la negativa a reparar los daños morales sufridos por el marido por el adulterio de la mujer ${ }^{74}$.

Tal como he sostenido en otras oportunidades, estimo que la jurisprudencia chilena se ha inclinado claramente por la tesis de la improcedencia de la indemnización de perjuicios derivados del mero incumplimiento de los deberes personales del matrimonio ${ }^{75}$. El fallo de la Corte Suprema del año $2014^{[76]}$-aunque con un trasfondo de violencia intrafamiliar y no de adulterio- es claro en ese sentido cuando le reconoce a la mujer divorciada el derecho a obtener la reparación de los perjuicios sufridos. En este punto puede establecerse un paralelo entre la decisión chilena y los "Fundamentos" del nuevo artículo 435 ccyc en su último párrafo77, porque la indemnización de los daños morales concedida a la mujer divorciada, según el fallo chileno antes citado, "no tienen su causa en el vínculo matrimonial en sí mismo ni en los deberes que de él emanan, sino en la condición de persona" de la víctima del daño. Es decir, los daños causados por las conductas antijurídicas del marido que fundaron el divorcio también habrían tenido que ser reparadas de no haber mediado matrimonio entre víctima y victimario ${ }^{78}$.

En definitiva, entonces, la comparación de los fundamentos dogmáticos de las tesis sobre la procedencia o improcedencia de la indemnización de perjuicios en favor del cónyuge víctima de un adulterio permite establecer que son comu-

73 Corte de Apelaciones de Santiago. Sentencia de fecha ro de noviembre de 2009 , rol n. ${ }^{\circ} 773^{8-}$ 07, confirmada por la Corte Suprema en sentencia de fecha 3 de junio de 201 2, rol n. ${ }^{\circ}{ }_{2} 6_{3}-20$ IO.

74 Esta sentencia se criticó, en su momento, por haber omitido que en el caso existía, además, el dolor del marido asociado al ocultamiento de la verdadera paternidad de uno de sus hijos. Cfr. Eтcheberry Court, L., "Responsabilidad civil ante el quebrantamiento del deber de fidelidad entre los cónyuges. Corte Suprema, I 3 de junio de 20 I 2", comentario de jurisprudencia, Revista Chilena de Derecho Privado, n. ${ }^{\circ}$ i 9, diciembre, 201 2, 2 I 5-2 I 8.

75 Turner, "Las circunstancias extraordinarias que harían procedente la indemnización de perjuicios entre cónyuges divorciados", cit., 236. En el mismo sentido, Varas Braun, J., "Corazón roto: ¿daño indemnizable?”, en Barría, M. (coord.), Estudios de derecho civil XI, Santiago, Thomson Reuters, 20I6, 248 y 249. TÁria Rodríguez, M., "Improcedencia de la indemnización por incumplimiento de deberes conyugales en la jurisprudencia chilena", en Barría Díaz et al. (eds.), Presente y futuro de la responsabilidad civil, cit., 234.

76 Corte Suprema. Sentencia de fecha 30 de diciembre de 2014, rol n. ${ }^{\circ}$ Io.622-I4, que confirmó el fallo de la Corte de Apelaciones de La Serena de fecha 3 de abril de 2014 , rol n. ${ }^{\circ}$ 507-201 3 .

77 Art. 435 ccyc, Fundamentos, último párrafo: "Los daños que pueden ser indemnizados a través del sistema general de la responsabilidad civil son aquellos que no tienen su causa en el vínculo matrimonial en sí mismo ni en los deberes que de él emanan, sino en la condición de persona. Se separa, así, lo relativo al vínculo matrimonial del derecho de daños".

78 Corral Talciani, H., "La incipiente jurisprudencia chilena sobre daños en la familia", en Revista de Derecho de Familia, Thomson Reuters, n. ${ }^{\circ}$, $2014,58$. 
nes en Argentina y Chile. Debidamente controvertidos por la doctrina, identificados y aplicados al caso concreto por la jurisprudencia, cabe concluir que ellos hacen, al menos, plausibles ambas posturas, tanto la de la procedencia como la de la improcedencia (con o sin limitaciones), pues existe la coherencia interna necesaria entre los argumentos que apoyan una u otra tesis.

En mi opinión, la experiencia argentina muestra que una vía para afirmar la improcedencia de la responsabilidad civil (tesis que, como adelanté en la introducción, he defendido reiteradamente) consiste en la reconfiguración de los deberes personales del matrimonio y del sistema de divorcio. Se trata de una fórmula doble: por un lado, se extrae del ámbito jurídico el deber de fidelidad matrimonial, catalogándolo como deber moral y, por otro, se elimina la noción de culpa en el divorcio. Esta decisión del legislador transandino no cierra completamente la posibilidad de argumentar en favor de la indemnización de perjuicios en caso de infidelidad, tal como se aprecia de las opiniones doctrinales disidentes y del fallo de la ciudad de General Pico referidos anteriormente. En este último se aprecia claramente cómo la recalificación del deber de fidelidad en deber moral no implica automáticamente la improcedencia de la reparación civil -pese al intento del tribunal por descartar una indemnización fundada en el mero hecho de la infidelidad-, porque cada vez que este adquiera cierta publicidad y el cónyuge que la sufra sea socialmente conocido, podrán surgir lesiones a intereses protegidos, como la dignidad o la integridad psíquica.

Sin embargo, estimo que la reforma legal en dos frentes -deberes personales de los cónyuges y divorcio incausado- refuerza enormemente la tesis de la improcedencia pues deja al cónyuge que sufrió la infidelidad sin un título legal que declare de manera inequívoca la culpa del infractor, que antes representaba la sentencia que acogía el divorcio por culpa y, por consiguiente, le exige la prueba del elemento subjetivo de la responsabilidad civil. Además, le obliga a acreditar la antijuridicidad del hecho sobre la base de un interés protegido distinto del mero cumplimiento de un deber matrimonial, es decir, de un interés independiente del hecho de la existencia del matrimonio.

En Chile se ha invocado el fallo argentino de General Pico a partir de la técnica interpretativa a fortiori: si en Argentina se afirma categóricamente la responsabilidad civil, siendo que en su ordenamiento jurídico no existe el divorcio por culpa y el deber de fidelidad es meramente moral, "con mayor razón habría que afirmarla en un ordenamiento como el nuestro en que existe el divorcio (y la separación judicial) por falta imputable y el deber de fidelidad no solo está consagrado legalmente como jurídico, sino que su incumplimiento, el adulterio, está declarado como una 'grave infracción' a dicho deber (art. I 32 del Código Civil)"79.

79 Corral Talciani, H., "Responsabilidad civil por adulterio: una mirada al otro lado de la cordillera", en El Mercurio Legal, 7 de junio de 2017, disponible en: http://www.elmercurio.com/ 
Por el contrario, el mismo argumento a fortiori podría utilizarse para sostener que si incluso ordenamientos jurídicos en los cuales tanto el texto como la intención del legislador son claros en relación con el carácter moral de la obligación de fidelidad no han podido zanjar una cuestión de este tipo, con mayor razón, dadas las controversias que se han suscitado en Chile, pareciera sensato abrir paso a una modificación legal del sistema de deberes matrimoniales tasados, actualmente vigente, y no continuar compilando argumentos a favor de una u otra posición que parecen haberse agotado. En su lugar, la consagración de un deber amplio, de contenido patrimonial y extrapatrimonial abierto, sensible a los cambios sociales referidos a la comprensión del matrimonio y adaptable a los mismos por la jurisprudencia, al modo del nuevo derecho matrimonial argentino, unido a un divorcio objetivo por cese de la convivencia, como el actualmente vigente en Chile, permitiría justificar de una forma jurídicamente coherente la improcedencia de la indemnización de perjuicios por adulterio de alguno de los cónyuges, tal como ha ocurrido, mayoritariamente, en Argentina.

\section{Conclusiones}

Con la entrada en vigencia del ccyc, el derecho matrimonial argentino se ha decantado por la improcedencia de la indemnización de perjuicios por el mero incumplimiento del deber de fidelidad entre cónyuges, sin perjuicio de algunas voces disidentes tanto en la doctrina como en la jurisprudencia. Tras una interesante evolución jurisprudencial y doctrinal, el legislador transandino optó por otorgarle a dicho deber la calidad de moral y por eliminar el divorcio por culpa. Mediante esta fórmula doble, la referida improcedencia resulta una consecuencia lógica de la reforma.

La experiencia argentina resulta muy valiosa para la cuestión en Chile en miras a la defensa de la improcedencia de la responsabilidad civil por la infracción del deber de fidelidad propio del matrimonio. Mientras la doctrina chilena se muestra dividida, invocando argumentos casi idénticos a los acuñados por la doctrina argentina durante más de 30 años de discusión en la materia, y la jurisprudencia niega la procedencia de la indemnización de perjuicios por el daño generado por los hechos constitutivos de la causal de divorcio por culpa, la reforma legal materializada en el ccyc muestra un camino deseable: la recalificación del deber de fidelidad y su erradicación como factor relevante para el divorcio constituyen vías idóneas para fundar sólidamente la tesis de la improcedencia. 


\section{Referencias}

Álvarez, O., "Código Civil y Comercial y daño moral con motivo del divorcio vincular", Revista La Ley 201 5-C.

Azar, A. y F. Ossola, "Principio de indemnidad, deber moral de fidelidad entre cónyuges y resarcimiento de daños", La Ley I4/I2/2016, cita online: AR/Doc/3787/2016.

Barbero, O., "La responsabilidad civil en el derecho de familia (30 años después)", Revista de Furisprudencia Argentina, 2005-IV, octubre-diciembre.

Belluscio, A.; E. Zannoni y A. Kemelmajer de Carlucci, Responsabilidad civil en el derecho de familia, Buenos Aires, Hammurabi, 1983 .

Bовrosky, J., "Matrimonio y divorcio", en Krasnow, A. (dir.), Manual de derecho de familia, Buenos Aires, Astrea, 2016.

Borda, G., "El daño moral en el matrimonio. La conveniencia de un nuevo plenario", Revista La Ley, 2005-C, 757 .

Borda, G., Tratado de derecho civil. Familia, ro. ${ }^{a}$ ed., t. I, La Ley, 2008.

Chechile, A., "El divorcio en el proyecto de Código Civil y Comercial de la Nación”, Revista de Derecho de Familia, n. 57.

Cifuentes, S., "El divorcio y la responsabilidad por el daño moral", Revista La Ley, I990B, 8०5-8 го.

Corral Talciani, H., "La incipiente jurisprudencia chilena sobre daños en la familia", Revista de Derecho de Familia, Thomson Reuters, n. ${ }^{\circ}$, 2014.

Corral Talciani, H., "Responsabilidad civil por adulterio: una mirada al otro lado de la cordillera", El Mercurio Legal, 7 de junio de 2017 , disponible en: http://www.elmercurio.com/Legal/Noticias/Analisis-Juridico/20 I 7/o6/o7/Responsabilidad-civilpor-adulterio-una-mirada-al-otro-lado-de-la-Cordillera.aspx? disp= I [consultado el 20 de octubre de 2017 ].

Dutro, R., Daños ocasionados en las relaciones de familia, Buenos Aires, Hammurabi, 2006.

Eтcheberry Court, L., "Responsabilidad civil ante el quebrantamiento del deber de fidelidad entre los cónyuges. Corte Suprema, I3 de junio de 20I2", comentario de jurisprudencia, Revista Chilena de Derecho Privado, n. ${ }^{\circ}$ I 9 , diciembre, 2012.

Fleitas Ortiz de Rozas, A. y E. Roveda, E., Manual de derecho de familia, 3. ${ }^{a}$ ed., Buenos Aires, Abeledo Perrot, 20 I I.

Giordano, V., "La reforma del código civil: pasado y presente desde una perspectiva de género", Mora (Buenos Aires), vol. 2 I , n. ${ }^{\circ}$ I, junio, 2015 , disponible en: http://www. scielo.org.ar/scielo.php?script=sci_arttext\&pid=S I 853-00IX20I 5000 I00006 [consultado el ro de octubre de 2015].

JALIL, J., "Daños derivados del divorcio y presupuestos para la procedencia de la responsabilidad civil", Revista Familia y Patrimonio, año 3, n. ${ }^{\circ}$ I, febrero, 20 I I.

Kemelmajer de Carlucci, A., "La eliminación del divorcio contencioso en el proyecto de Código Civil y Comercial de la República Argentina y su incidencia en el derecho de daños", en Lepin, C. y D. Vargas (eds.), Responsabilidad civil y familia, Santiago, Thomson Reuters, 20I4, $20 \mathrm{I}-208$. 
Kemelmajer de Carlucci, A., "Lineamientos generales del derecho de familia en el proyecto de Código Civil y Comercial unificado. Por qué no al maquillaje”, Revista de Derecho Privado y Comunitario, Rubinzal-Culzoni, 20 12-2, I.

Kemelmajer de Carlucci, A.; M. Herrera y N. Lloveras (dir.), Tratado de derecho de familia, t. v-A, r. ${ }^{\text {a }}$ ed. revisada, Santa Fe, Rubinzal-Culzoni, 20 I6.

Kemelmajer de Carlucci, A.; M. Herrera y N. Lloveras (dir.), Tratado de derecho de familia, t. I, Santa Fe, Rubinzal-Culzoni, 2014.

Krasnow, A. (dir.), Manual de derecho de familia, Buenos Aires, Astrea, 20 r6.

Krasnow, A., "Limitaciones a la reparación del daño en el divorcio. Una tendencia que crece", Revista de Responsabilidad Civil y Seguros, La Ley, año xII, n. ${ }^{\circ}$ Iо, octubre, 20 Iо.

Medina, G., "Daños en el derecho de familia en el Código Civil y Comercial”, Revista de Responsabilidad Civil y Seguros, La Ley, año xviı, n. ${ }^{\circ}$ 4, abril, 2005.

Medina, G., Daños en el derecho de familia, Santa Fe, Rubinzal-Culzoni, 2002.

Mızrahi, F., Familia, matrimonio y derecho, 2. .a ed., Buenos Aires, Astrea, 2006.

Molina de Juan, M., "Derechos y deberes de los cónyuges”, en Kemelmajer de Carlucci, A.; M. Herrera y N. Lloveras (dirs.), Tratado de derecho de familia, t. I, Santa Fe, Rubinzal-Culzoni, 2014 .

Molina de Juan, M., "Disolución del matrimonio", en Kemelmajer de Carlucci, A.; M. Herrera y N. Lloveras (dirs.), Tratado de derecho de familia, t. I, Santa Fe, RubinzalCulzoni, 20I4.

Mosset Iturraspe, J., "Los daños emergentes del divorcio”, Revista La Ley, I983-C.

Sambrizzi, E., "Subsistencia del deber de fidelidad durante la separación de hecho y daño moral derivado de la causal de adulterio", Revista La Ley, 2005-C.

Sambrizzi, E., Daños en el derecho de familia, Buenos Aires, La Ley, 200 I.

Tapia Rodríguez, M., "Divorcio y responsabilidad civil en el derecho chileno”, Revista de Derecho de la Universidad de Concepción, n. ${ }^{\circ}$ 239, año Lxxxıv, enero-junio, 2016.

TAPia Rodríguez, M., "Improcedencia de la indemnización por incumplimiento de deberes conyugales en la jurisprudencia chilena”, en Barría Díaz, R. et al. (eds.), Presente y futuro de la responsabilidad civil, Santiago, Thomson Reuters, $20 \mathrm{I} 7$.

Turner, S., "Indemnización de perjuicios a propósito del divorcio por culpa", en Barría Díaz, R. et al. (eds.), Presente y futuro de la responsabilidad civil, Santiago, Thomson Reuters, 2017 .

Turner, S., "Las circunstancias extraordinarias que harían procedente la indemnización de perjuicios entre cónyuges divorciados", en Barría Paredes, M. (ed.), Estudios de derecho civil XI, Santiago, Thomson Reuters, 20 I6.

Varas Braun, J., “Corazón roto: ¿¿daño indemnizable?”, en Barría Paredes, M. (coord.), Estudios de derecho civil XI, Santiago, Thomson Reuters, 20 I6.

Zannoni, E. et al. (revisores), Código Civil y Comercial. Concordado con el régimen derogado y referenciado con legislación vigente, 2. ${ }^{\mathrm{a}}$ reimp., Buenos Aires, Astrea, $20 \mathrm{I} 5$. 